\section{Nucleosome positioning by the winged helix transcription factor HNF3}

\author{
Eun Yong Shim, ${ }^{1}$ Christopher Woodcock, ${ }^{2}$ and \\ Kenneth S. Zaret ${ }^{1,3}$ \\ ${ }^{1}$ Department of Molecular Biology, Cellular Biology, and \\ Biochemistry, Brown University, Providence, Rhode Island \\ 02912 USA; ${ }^{2}$ Department of Biology, University of \\ M assachusetts, Amherst, Massachusetts 01003 USA
}

\begin{abstract}
Nucleosome positioning at genetic regulatory sequences is not well understood. The transcriptional enhancer of the mouse senum al bumin gene is active in liver, where regulatory factors occupy their target sites on three nucleosomelike particles designated N1, N2, and N3. The winged helix transcription factor HNF3 binds to two sites near the center of the N1 particle. We created dinucleosome templates using the albumin enhancer sequence and found that site-specific binding of HNF3 protein resulted in nucleosome positioning in vitro similar to that seen in liver nuclei. Thus, binding of a transcription factor can position an underlying nucleosome core.
\end{abstract}

Received September 12, 1997; revised version accepted N ovember 5, 1997.

The basic unit of chromatin is the nucleosome core particle, which consists of DNA wrapped nearly twice around an octamer of the four core histone proteins. Recent studies have reveal ed nucleosomes to be structurally dynamic and integral to transcriptional regulation (Felsenfeld 1992). For example, nucleosomes become positioned at certain yeast promoters when they are silent, with the octamers occluding basal transcription components from the DNA (Han et al. 1988; Shimizu et al. 1991). In other cases, positioned nucleosomes juxtapose transcription factor binding sites in linker DNA on either side of the particles, thereby stimulating transcriptional activity (Lu et al. 1993; Jackson and Benyajati 1993; Schild et al. 1993; Verdin et al. 1993). At the serum al bumin gene in mouse, the N 1, N2, and N 3 nucleosomes are positioned over the transcriptional enhancer only in the liver, when the enhancer is active, and factor binding sites map to the particles themselves, not linker DNA (McPherson et al. 1993; Zaret 1995). Recent studies of the mouse mammary tumor virus (MMTV) and human immunodeficiency virus (HIV) promoters have reveal ed nucleosomes positioned over essential transcription factor-binding sites in both the active and silent states (Fragoso et al. 1995; Truss et al. 1995; Verdin et al. 1993; Steger and Workman 1997). Given the presence of posi-

[Key Words: Nucleosome; winged helix factor; HNF3; enhancer; chromatin]

${ }^{3}$ Corresponding author

E-MAIL zaret@brown.edu; FAX (401) 863-1348. tioned nucleosomes in diverse regulatory contexts, we have investigated how particles become positioned during gene regulation.

For some genes, the DNA sequence itself positions a nucleosome core (Rhodes 1985; Perlmann and Wrange 1988; Hayes et al. 1990; Piña et al. 1990; Archer et al. 1991). Alternatively, regulatory DNA sequences may not be disposed to position nucleosomes (McPherson et al. 1996), and bound factors may either serve as a boundary against which a nucleosome can resi de (Fedor et al . 1988; Pazin et al. 1997) or actively position nucleosomes nearby (Roth et al. 1992). N o positioning mechanism has yet been described for a protein that binds to DNA on nucleosomes, yet many factors are capable of binding nucleosomal DNA, al beit with lower efficiency than free DN A (see A dams and Workman 1995).

Two specific binding sites for the transcription factor HNF3, designated eG and eH, occur near the middle of the positioned N 1 particle at the albumin enhancer in liver nuclei (M cPherson et al. 1993). HNF3 binding to both of the sites is required for enhancer activity (Liu et al. 1991; Jackson et al. 1993), and in vivo footprinting of endodermal tissue from mouse embryos has shown that the $\mathrm{E}$ site is occupied before the albumin gene is activated in development (Gualdi et al. 1996). Thus, HNF3 acts at one of the earliest steps in gene activation.

The isoforms HNF3 $\alpha, \mathrm{HNF} 3 \beta$, and HNF3 $\gamma$, and their homolog in Drosophila, fork head, activate many genes during gut development in mammals and flies (Weigel et al. 1989; Lai et al. 1991), and together constitute a subgroup of winged-helix factors that regulate genes in many different developmental contexts (Kaufmann and Knochel 1996). The winged helix DNA-binding motif contains tertiary structure similar to the globular domain of linker histone (Clark et al . 1993; Ramakrishnan et al. 1993), and because linker histones can bind and compact chromatin (reviewed by Zlatanova and van Hol de 1996), transcription factors containing the winged helix domain may al so possess special nucleosome binding properties. When a plasmid bearing the al bumin enhancer is assembled into polynucleosomes using a Drosophila embryo extract, a nucleosome is positioned over the $\mathrm{eG}$ and eH sites of the enhancer (McPherson et al. 1993). The D rosophila embryo extract has an HNF3/fork head-like binding activity, and mutation of the eG HNF3-binding site disrupted nucleosome positioning over the enhancer (M cPherson et al . 1993). These studies reveal ed that winged helix factor binding helps position a nucleosome at the serum albumin gene enhancer. However, they did not address whether HNF3 binding alone is sufficient for nucleosome positioning or whether a complex with other proteins is critical.

In the present study, we investigated whether HNF3 binding to specific sites in a multinucleosome array is sufficient to position a nucleosome. The results reveal a new mechanism for nucleosome positioning and a direct role for winged helix transcription factors in organizing chromatin. 


\section{Results}

Dinucleosomes of albumin enhancer DNA are randomly positioned in vitro

To investigate the ability of purified HNF3 to affect nucleosome positioning, we created dinucleosomes in vitro with a 428-bp template that spanned both the N 1 and $\mathrm{N} 2$ nucleosomelike particles observed on the albumin enhancer in liver nuclei (M cPherson et al . 1993) (Fig. 1A). We al so created dinucleosomes that had point mutations at the two HNF3-binding sites eG and eH; the sites are essential for enhancer activity in transfected cells (Liu et al. 1991; Jackson et al. 1993). On wild-type and $\mathrm{eG}^{-} / \mathrm{eH}^{-}$mutant templates, two histone octamers would span a total of $290 \mathrm{bp}$, leaving 140 bp for different nucleosome positions. The 180-bp sequence of the $\mathrm{N} 1$ particle in liver nuclei does not position nucleosomes in vitro (M cPherson et al . 1996), so we anticipated that the larger amount of free DNA on 428-bp dinucleosome templates would allow us to assess the ability of HNF3 to position nucleosomes.

Dinucleosomes were assembled with purified core histones and label ed DNA and then purified from mononucleosomes and free DNA on glycerol gradients. Phosphorlmager quantitation showed that the pooled dinucleosome fractions contained $93 \%-95 \%$ dinucleo-

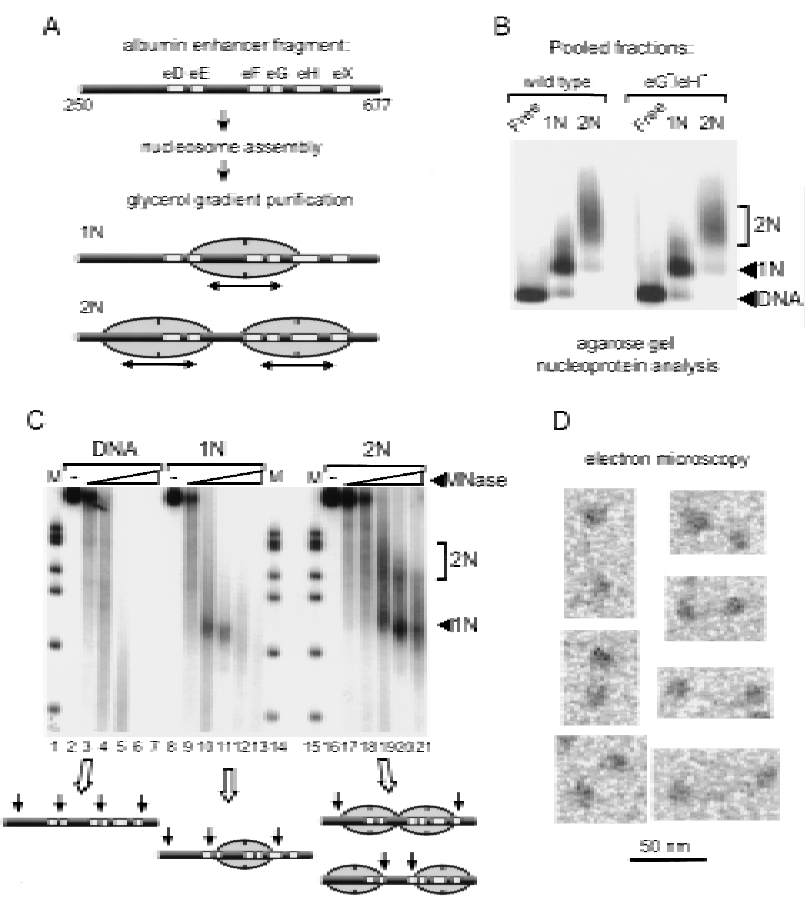

Figure 1. Assembly and characterization of al bumin enhancer dinucleosomes. (A) A 428-bp al bumin enhancer fragment used for nucleosome assembly; end positions on the enhancer sequence (Liu et al. 1991) are shown (top). Transcription factor binding sites $\mathrm{eD}$ to $\mathrm{eX}$ are indicated. Arrows bel ow ovals (core particles) indicate random positioning. (B) Agarose gel analysis of gradient fractions. (C) DNA from $M N$ ase digestion of free DNA, mononucleosomes (1N), and dinuclueosomes (2N). (M) фX174 marker; (1N) mononucleosome-sized intermediates; $(2 \mathrm{~N})$ additional material in the dinucleosome fraction. (D) Electron microscopic analysis of dinucleosome samples. somes (Fig. 1B). To assess the integrity of the pooled fractions, they were treated with micrococcal nuclease (M N ase), and DN A was isolated and examined by native gel electrophoresis (Fig. 1C). MNase makes doublestranded cuts in linker DNA and should give rise to a 146-bp digestion intermediate attributable to protection by the histones. As expected, when the mononucleosomes were treated with $\mathrm{MN}$ ase, it resulted in a 146-bp digestion product, whereas the free DNA was uniformly digested (Fig. 1C, lanes 2-13). In contrast, the dinucleosomes were far more resistant to $\mathrm{MN}$ ase and yielded products of $\sim 140$ and $290 \mathrm{bp}$, with a variety of digestion intermediates (Fig. 1C, Ianes 16-19). Given the potential range of linker sizes of up to $140 \mathrm{bp}$ on the 428-bp dinucleosome templates, the digestion products suggest that nucleosomes are randomly positioned. In contrast, nucleosomes that are regularly spaced in a population, with uniform linker lengths, will give rise to a "Iadder" of digestion products that are multiples of the unit repeat length. When the albumin enhancer dinucleosomes were further digested with $\mathrm{MN}$ ase, products of 146 bp began to accumulate, as expected (Fig. $1 C$, lanes 20,21). We also visualized the dinucleosomes under the electron microscope (Fig. 1D). Over $85 \%$ of the 179 complexes seen were dinucleosomal, with the re mainder mononucleosomal. Various linker lengths and nucleosome positions were observed (Fig. 1D). We infer that the dinucleosome fractions exhibit expected structural properties and that the albumin enhancer DN A sequence does not intrinsically position nucleosomes.

\section{HNF3 $\alpha$ binds its target sites on dinucleosome templates}

We used a DN ase I footprinting assay to assess whether purified HNF3 protein could bind its sites on the albumin enhancer dinucleosomes. With free DNA at a $4 \mathrm{~nm}$ concentration, a $16 \pm 8 \mathrm{~nm}$ concentration of HNF3 gave $\sim 70 \%$ saturation of the eG site, whereas $24 \pm 10 \mathrm{~nm}$ $\mathrm{HNF3}$ was required to $70 \%$ saturate the eH site (average \pm .D. of four experiments with different template preparations; see Fig. 2A, Ianes 2-5). The slightly higher affinity of HNF3 for the eG site on free DNA was observed in previous footprint titration studies, with the template concentration below the dissociation constant, as was DN ase I hypersensitivity within the HNF3 footprints (Zaret and Stevens 1995). The nucleosome concentrations used in all experiments herein, $2 \mathrm{ng} / \mu \mathrm{l}$, is within that required for nucleosome stability in vitro (Godde and Wolffe 1995). With a 4 nM concentration of dinucleosomes, $30 \mathrm{~nm}$ of HNF3 resulted in simultaneous occupancy of both the eG and eH sites and DN ase hypersensitivity, but at both sites the footprints were smaller than that observed on free DNA (Fig. 2A, lanes 10,11). Thus, HNF3 binds the eG and eH sites on the dinucleosomes with an affinity that is altered from that for the sites on free DNA and with a qualitatively different footprint. These effects would not be predicted if HNF3 bound to eG and eH sites that might be exposed in randomly positioned linker DN A between two nucleosome particles, or if HNF3 binding destabilized the nucleosomes so that the protein bound to free DNA. Binding experiments with templates containing clustered point 


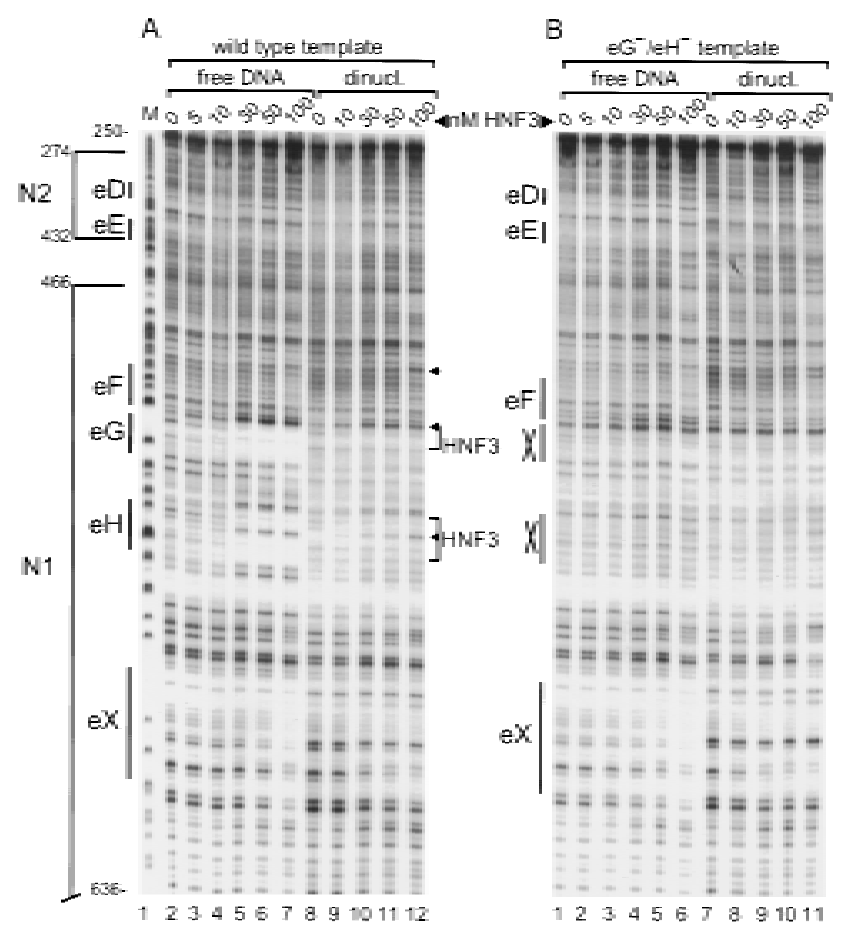

Figure 2. DNase I footprinting of HNF3 bound to dinucleosomes. (A) Wild-type enhancer templates. (Lane 1) G sequencing reaction. Brackets indicate positions of the $\mathrm{N} 1$ and $\mathrm{N} 2$ particles in liver nuclei (M cPherson et al. 1993). N umbers at left indicate enhancer positions of liver particle boundaries; numbers at top and bottom indicate extent of enhancer sequence. (B) Templates containing mutations of the HNF3-binding sites. At $100 \mathrm{~nm}$ HNF3, some nonspecific hypersensitive cleavages on the templates is observed, but no footprints.

mutations of the $\mathrm{eG}$ and $\mathrm{eH}$ HNF3 sites failed to reveal DN ase I footprints (Fig. 2B). We conclude that HNF3 binds the $\mathrm{eG}$ and $\mathrm{eH}$ sites on nucleosomes with an affinity that is altered from its relative affinity for the sites on free DNA and with an approximately fivefold lower affinity for nucleosomal versus free DNA.

Wealso observed DN ase I protections on the di nucleosomes in the vicinity of the eX site, which binds HNF3 at very high concentrations on free DNA (Fig. 2A, cf. lanes 7 and 12), as well as DNase hypersensitivity at a site upstream of the eF footprint (Fig. 2A, arrowhead beside lane 12), where HNF3 binds selectively to mononucleosome core particles (Cirillo et al. 1998); both of these sites occur within the region of the $\mathrm{N} 1$-positioned particle seen in liver nuclei. No clear HNF3 footprints were observed in the far upstream regi on of the template, which spans the N2 particle in liver nuclei.

HNF3 positions a nucleosome underlying its binding site

Given the ability of HNF3 to bind its target sites on the dinucleosomes and the random positioning of the particles, we could address whether or not HN F3 influences nucleosome positioning. We previously developed a modification of the ligation-mediated PCR (LM-PCR) procedure, which selectively detects double-stranded M N ase cleavages in chromatin (M cPherson et al. 1993); such cleavages occur preferentially in linker DNA. We therefore incubated increasing amounts of HNF3 with dinucleosome or free DNA templates, and treated the complexes with $\mathrm{MN}$ ase and used LM-PCR to map the positions of double-stranded cleavages. To compare the $\mathrm{MN}$ ase digestion of wild-type and $\mathrm{eG}^{-} / \mathrm{eH}^{-}$site mutant templates, we analyzed digestion products on native polyacrylamide gels (data not shown). Wild-type and $\mathrm{eG}^{-} / \mathrm{eH}^{-}$templates that were cleaved to similar extents by $\mathrm{MN}$ ase at a given $\mathrm{HN} \mathrm{F} 3$ concentration were then analyzed by LM-PCR.

$M N$ ase cleavages at the $3^{\prime}$ half of the enhancer fragment, which span the HNF3 sites, were mapped with a set of primers that display sequences from enhancer positions 515-677 (Fig. 3, A, left, and D). In the absence of HNF3, the dinucleosomes exhibited a cleavage pattern that resembled free DN A (Fig. 3, A cf. lane 2, and B, lanes 1 and 2), providing clear evidence that nucleosomes were randomly distributed al ong the DNA. We used relatively low amounts of $\mathrm{MN}$ ase in these assays (see Fig. $1 \mathrm{C}$, lane 17); higher levels led to the mono- and dinucleosomesized products seen in Figure 1C. Adding HN F3 to free wild-type DNA caused regions of enhanced MNase

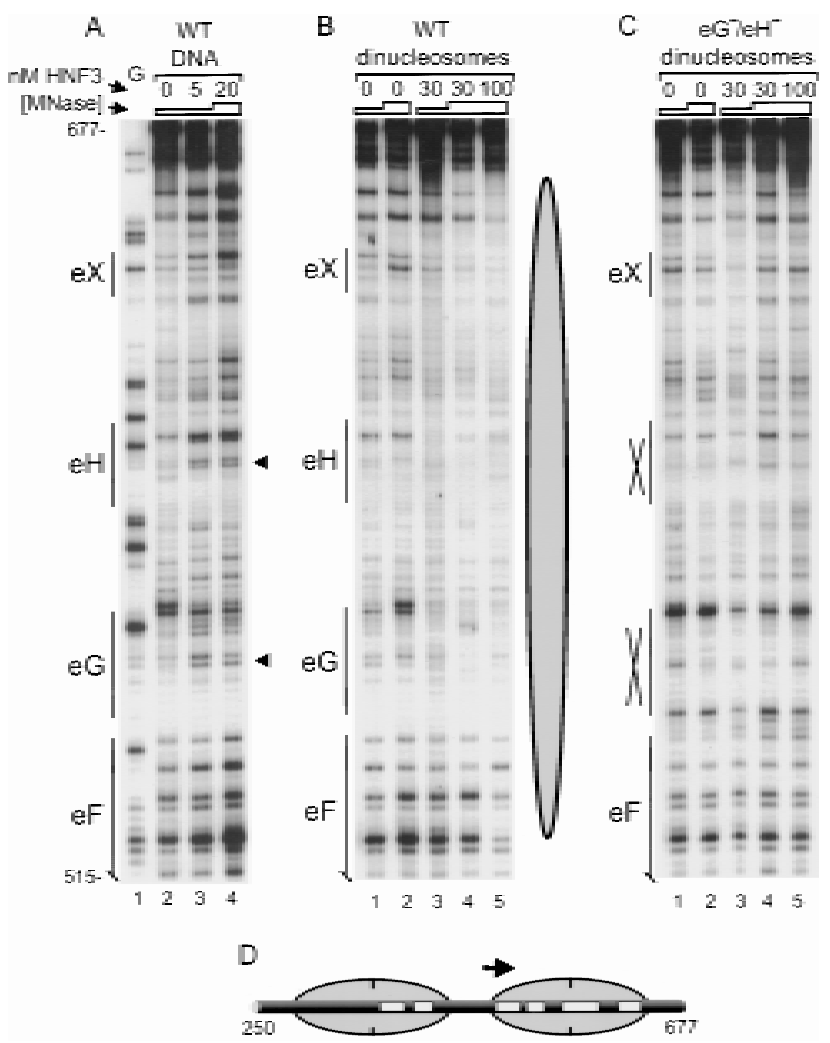

Figure 3. Nucleosome positioning by HNF3. (A-C) 4 nM concentrations of free DNA or dinucleosomes were incubated with HNF3 and digested with MN ase for five min. Double-stranded $M N$ ase cleavage sites were mapped by LM-PCR. The labeled primer position is depicted in D. (A) (Lane 1) G cleavage; (lanes 2,3) $0.015 \mathrm{U} / \mathrm{ml}$ of $\mathrm{M} \mathrm{N}$ ase; (lane 4) $0.05 \mathrm{U} / \mathrm{ml}$. (B,C) (Lanes 1,3) $0.025 \mathrm{U} / \mathrm{ml}$; (lanes $2,4,5) 0.05 \mathrm{U} / \mathrm{ml}$. The oval at the right of $B$ marks the region of $\mathrm{MN}$ ase protection upon HNF3 binding to the wild-type dinucleosomes. Data in all panels are from the same gel. 
cleavages within the eG and eH sites (Fig. 3A, lanes 3,4, arrowheads). Strikingly, we reproducibly observed the opposite effect on the dinucl eosome templates; that is, a large region of protection from $\mathrm{MN}$ ase occurred as HN F3 was added (Fig. 3B, lanes 3-5; large oval at right). The protected regi on extended from the priming site to about enhancer position 636, 41 bp before the end of the fragment. Addition of HNF3 to the wild-type dinucleosome templates did not el icit $\mathrm{MN}$ ase hypersensitivity within the HNF3 footprints (Fig. 3B), as it did with free DNA, demonstrating that the majority of the signal was not due to HNF3 binding to free DNA, which conceivably could be generated by factor binding. Importantly, no general protection from $\mathrm{MN}$ ase was observed when HNF3 was added to the dinucleosomes with the $\mathrm{eG}^{-} / \mathrm{eH}^{-}$ site mutations (Fig. 3C), demonstrating that site-specific binding by HNF3 is necessary. The apparent 3 ' boundary of $\mathrm{MN}$ ase cleavages on the wild-type dinucleosomes with bound HNF3 corresponds closely to the $3^{\prime}$ boundary of the albumin enhancer N 1 particle seen in mouse liver chromatin, at position 642 (M cPherson et al. 1993).

To map upstream M N ase cleavages, we used LM -PCR primers that displayed enhancer positions 550-250 (Fig. 4, A, left, and D). Cleavages on dinucleosomes without HNF3 appeared similar to those on the free DN A, indicating random nucl eosome positioning (Fig. 4, A, lane 3, and B, lanes 1 and 2). Adding HNF3 to free DNA led to several regions of $M N$ ase hypersensitivity, including those within the eG site and el sewhere (Fig. 4A, Iane 4, arrowhead). However, on the wild-type dinucleosomes, but not the $\mathrm{eG}^{-} / \mathrm{eH}^{-}$dinucleosomes, addition of HNF3 led to general ized protection up to enhancer position 468 (Fig. 4B, lanes 3-5; bottom oval at right). The latter position corresponds well to the position of the 5 ' boundary of the N 1 particle in liver chromatin, at nucleotide 466 (McPherson et al. 1993). Again, the lack of M N ase hypersensitivity within the $\mathrm{EG}$ site on the dinucleosome particles with HN F3 bound indicates that the protection pattern is not due to HNF3 binding a putative free DN A subpopulation of templates. In conclusion, specific binding of HNF3 to its target sites causes the positioning of an underlying nucleosome at sequences closely approximating those seen at the albumin enhancer in mouse liver nuclei.

Positioning of a nucleosome array

Remarkably, when HNF3 was added to wild-type dinucleosomes, but not the $\mathrm{eG}^{-} / \mathrm{eH}^{-}$mutant templates, a second large regi on of protection was observed extending from about enhancer position 269 to 432 (Fig. 4B, lanes 3-5; top oval at right). The protected area corresponds closely to the region protected by the $\mathrm{N} 2$ albumin enhancer particle in liver nuclei, from position 274 to 432 (McPherson et al. 1993). Individual sites of protections and enhancements occurred in the apparent linker DN A between the particles on wild-type dinucleosomes (Fig. $4 \mathrm{~B}$, dots at right). We conclude that when HNF3 positions a nucleosome core underlying its binding sites in vitro, it causes the positioning of an adjacent core particle. The positions of both particles are strikingly simi- lar to those observed when HNF3 is bound to enhancer chromatin in vivo.

\section{Discussion}

Our previous studies established a correl ation between the presence of the transcription factor HNF3 at the eG and eH sites of the al bumin enhancer, as detected by in vivo footprinting, and the presence of a positioned nucleosomelike particle underlying the HNF3 sites in liver nuclei (MCPherson et al. 1993). In transfected cells, the two HNF3 sites are essential for transcriptional stimulation by the enhancer (Liu et al. 1991; Jackson et al. 1993). In the present study, we discovered that HNF3 binding to its enhancer sites is both necessary and sufficient to position an underlying nucleosome core in vitro. Therefore, we suggest that a function of the winged helix factor HNF3 is to help organize the chromatin of particular target genes. Considering that HNF3 regulates nearly all known genes expressed in endoderm-derived tissues (Costa 1994) and that $>80$ other winged helix regulatory factors have been identified (Kaufmann and Knochel 1996), most of which play developmental roles in controlling gene expression, the nucleosome positioning properties of HNF3 may be representative of a generally important mechanism for chromatin remodeling (Zaret 1995).

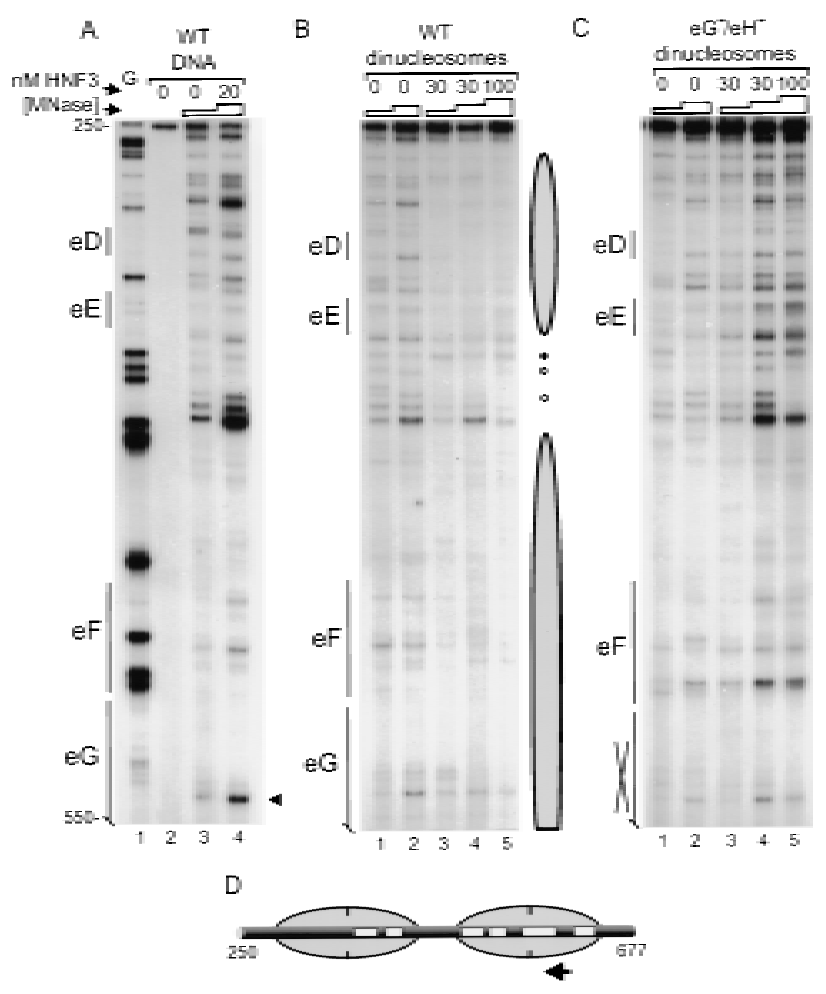

Figure 4. Positioning of a nucleosome array. (A) (Lane 1) G cl eavage; (lane 2) no M N ase; (lanes 3,4) 0.075 and $0.15 \mathrm{U} / \mathrm{ml}$ of $\mathrm{MN}$ ase, respectively, for $1 \mathrm{~min}$ digestion. $(B, C)$ (Lanes 1,3$) 0.075$ $\mathrm{U} / \mathrm{ml}$; (lanes 2,4) $0.15 \mathrm{U} / \mathrm{ml}$; (lane 5) $0.25 \mathrm{U} / \mathrm{ml}$; all for $1 \mathrm{~min}$ digestion. The ovals at the right of $\mathrm{B}$ mark $\mathrm{MN}$ ase-protected regions. and $\bigcirc$ at right in $B$ indicate enhanced and protected sites, respectively, of $\mathrm{MN}$ ase cleavage. Data in all panels are from the same gel. (D) Priming strategy. 
By various criteria, including DN ase I and $\mathrm{MN}$ ase assays and electron microscopy, nucleosomes are randomly positioned on al bumin enhancer DNA in the absence of HNF3. The lack of intrinsic nucleosome positioning properties of the enhancer DNA, both in vitro (McPherson et al. 1996; this study) and in nonliver tissues in vivo (McPherson et al. 1993), may allow the enhancer to be sensitive to the nucleosome positioning effects of HNF3.

Regarding the mechanism of positioning, note that HNF3 bends DN A slightly toward the protein (Clark et al. 1993; Pierrou et al. 1994). If HNF3 bound the side of DNA as it curves around the core histones, or inside the gyre, as has been proposed recently for winged helix linker histones (Pruss et al. 1996), then HNF3 binding might help DNA bend around the histone octamer and thereby stabilize the position of the core particle. More generally, the combination of HNF3, core histones, and DN A sequence may stabilize a DNA distortion that favors wrapping of the DNA around the histone octamer.

The winged helix DNA-binding motif occurs both in HNF3-related transcription factors and in linker histones (Clark et al. 1993; Ramakrishnan et al. 1993). DN ase I footprinting studies of mixed-sequence dinucleosomes showed that linker histones can protect DNA near the dyad axis (Staynov and Crane-Robinson 1988), where the HNF3 binding sites occur on the albumin enhancer-positioned particles. However, recent studies of mononucleosomes of the Xenopus 5S rRN A gene indicate that linker histones can bind to the edge of the particle (Pruss et al. 1996), and in a study of HNF3 binding to mononucleosomes of the albumin enhancer $\mathrm{N} 1$ sequence, we found a third HNF3 binding site at the edge of the particle (Cirillo et al. 1998). We observed binding of HN F3 to this site on dinucleosome templates, as seen by DNase hypersensitivity in Figure 2A and by other experiments where clear footprints were evident (data not shown). The functional role of HNF3 binding to sites other than eG and eH remains to be explored. It is clear, though, that specific binding of HNF3 to its previously characterized target sites on the enhancer dinucleosomes is essential for nucleosome positioning and that the resulting particles are positioned with the HNF3 sites in the vicinity of the dyad axis.

Partial M Nase digestion revealed an $\sim 168$-bp region of protection spanning the al bumin enhancer HNF3 sites, a size greater than that expected for a nucleosome core particle. Careful MN ase mapping studies of the MMTV promoter in vivo has shown that what appears to be a positioned nucleosome in a population of templates actually may be a family of similarly but not identically positioned particles in the population (Fragoso et al. 1995). We attribute the apparently large size of the HNF3-bound particles to a bias of MNase for DNA sequence at the low enzyme concentration used for mapping, as well as to the possibility that the 168-bp region may span a family of different but closely related nucleosome positions. Regardless of the exact boundaries of particles bound by HNF3, a nucleosome becomes positioned within the region that is spanned by the al bumin enhancer N 1 particle in liver nuclei. Thus, the nucleosome position caused by HNF3 binding in vitro closely reconstitutes that observed when HNF3 is bound to the albumin enhancer in vivo.

Understanding how nucleosomes become positioned at eukaryotic gene regulatory el ements provides insight into the ways that changes in chromatin structure can be regulated during gene control. The discovery that a member of a large class of transcription factors can directly control nucleosome position indicates that such chromatin changes are likely to be integral to the developmental control of many downstream genes. Future studies will be directed toward understanding the regulatory role of positioning and the specific factor-nucleosome interactions that are necessary for positioning to occur.

\section{Materials and methods}

Preparation of dinucleosome substrates and mouse HNF3 $\alpha$ End-label ed DN A fragments were created by PCR using oligonucleotides phosphorylated with [ $\gamma^{-32}$ P]ATP. Internally labeled DNAs were generated by $\left[\alpha^{-32} \mathrm{P}\right] \mathrm{dATP}$ and $\left[\alpha^{-}{ }^{32} \mathrm{P}\right] \mathrm{CCTP}$ in PCRs. Primers for preparative DNA synthesis were GGCAACCCACACATCCTTAGGCAT (top) and CATACTAAACGTAGACAAGTTGGCC (bottom). Either the wild-type enhancer or one with $\mathrm{EG}$ and $\mathrm{eH}$ HNF3 site mutations was used as template (Cirillo et al. 1998). After PCR, labeled DN As were gel-purified and specific activities determined by $\mathrm{OD}_{260}$ and scintillation counting. Twenty micrograms of purified PCR product and $16 \mu \mathrm{g}$ of core histones were assembled into nucleosome cores by gradient dialysis against salt and urea as described (M cPherson et al. 1996), except with HEPES buffer (pH 7.4) instead of Tris. Dinucleosomes were purified from mononucleosome core particles and free DN A by centrifugation in 16\%-18\% glycerol gradients (5 ml) in a buffer containing $50 \mathrm{~mm}$ HEPES-N aOH (pH 7.4), 1 $\mathrm{mm}$ EDTA, and $0.03 \mathrm{mg} / \mathrm{ml}$ of BSA. After centrifugation at 35,000 rpm in a SW50.1 rotor for $18 \mathrm{hr}$ at $4^{\circ} \mathrm{C}, 150-\mu \mathrm{l}$ gradient fractions were collected. Aliquots were el ectrophoresed on $0.7 \%$ agarose gels in $0.5 \times \mathrm{TBE}$ at $4{ }^{\circ} \mathrm{C}$, and fractions containing dinucl eosomes were pool ed and dialyzed against a solution of $10 \mathrm{~mm}$ HEPES (pH 7.4), $10 \mathrm{~mm} \mathrm{~N} \mathrm{aCl}$, and $1 \mathrm{~mm}$ 2-mercaptoethanol. After dialysis, samples were concentrated with Centricon 10 filters at $5000 \mathrm{rpm}$ in an SS34 rotor until nucleosomes were at $15 \mathrm{ng} / \mu \mathrm{l}$ or greater, and then were stored in siliconized tubes at $4^{\circ} \mathrm{C}$. Electron microscopic analysis was performed on dinucleosome samples that were fixed in $0.1 \%$ glutaral dehyde, adsorbed to gl ow-discharged carbon films, and stained with ethanolic phosphotungstic acid (Bednar et al. 1995). Mouse HNF3 $\alpha$ protein with a 6-histidine amino-terminal tag was purified from E. coli as described (Zaret and Stevens 1995; Cirillo et al. 1998). The molecular weight of the recombinant HNF3 $\alpha$ was 54,500 .

Binding reactions and enzymatic assays

HN F3-binding reactions were carried out in 20- $\mu$ l volumes containing 4 nM $(2 \mathrm{ng} / \mathrm{ml})$ of free DNA or dinucleosomes. Purified HNF3 was diluted in $20 \mathrm{~mm}$ HEPES (pH 6.5), $5 \mathrm{~mm}$ dithiothreiotol, $1 \mathrm{~mm} \mathrm{M} \mathrm{gCl}, 400 \mathrm{~mm}$ $\mathrm{KCl}, 20 \%$ glycerol, $0.1 \% \mathrm{NP}-40$, and $0.25 \mathrm{mg} / \mathrm{ml}$ of BSA. HNF3 was incubated with the substrates in $10 \mathrm{~mm}$ Tris- $\mathrm{HCl}(\mathrm{pH} 7.5), 1 \mathrm{~mm} \mathrm{M} \mathrm{gCl}$, $5 \mathrm{~mm}$ DTT, $40 \mathrm{~mm} \mathrm{KCl}, 0.5 \%$ glycerol, $0.35 \mathrm{mg} / \mathrm{ml}$ of BSA, and $1 \%$ Ficoll, and the reactions were incubated at $23^{\circ} \mathrm{C}-25^{\circ} \mathrm{C}$ for $30 \mathrm{~min}$. DN ase I concentrations of 0.05 and $0.175 \mu \mathrm{g} / \mathrm{ml}$ were used with end-labeled free DNA and dinucleosomes, respectively, as described (M cPherson et al. 1996). Autoradiographs of footprinting gels were scanned, footprinted regions were quantitated by densitometry, and data points from $10 \%$ to $90 \%$ saturation were plotted to determine the $70 \%$ saturation value. For $\mathrm{MN}$ ase analysis, 20- $\mu$ l binding reactions were adjusted to $0.5 \mathrm{~mm} \mathrm{CaCl}$, treated with $1 \mu \mathrm{l}$ of $\mathrm{MN}$ ase, the latter diluted in $5 \mathrm{~mm}$ Tris- $\mathrm{HCl}(\mathrm{pH} 7.5)$, $25 \mu \mathrm{M} \mathrm{CaCl}{ }_{2}$ to final concentrations of $0.015-0.1 \mathrm{U} / \mathrm{ml}$ of $\mathrm{M} \mathrm{N}$ ase. Reactions were incubated at $23^{\circ} \mathrm{C}-25^{\circ} \mathrm{C}$ and stopped with EGTA to $5 \mathrm{~mm}$. Portions of the recovered DNAs were kinased with [ $\gamma^{-32}$ P]ATP, precipitated, and subjected to nondenaturing polyacrylamide $(6 \%)$ gel electrophoresis to assess the extent of double-stranded $M N$ ase cleavage of each sample. Data shown are representative of experiments with independent preparations of al bumin enhancer dinucleosome templates. 
Analysis of nucleosome boundaries by LM-PCR

Double-stranded $\mathrm{MN}$ ase cleavages in HNF3 binding reactions were mapped by LM-PCR as described (M cPherson et al. 1993). Briefly, $66 \mathrm{pg}$ of DNA from each MN ase reaction was kinased with ATP, subjected to ligation with a double-stranded linker, and analyzed by PCR and labeling reaction steps. The albumin enhancer positions and sequence of oligonucleotide used are enhancer top strand (Fig. 3), T1, (485) TGTGTCTCCTGCTCTG (500); T2, (500) GTCAGCAGGGCACTGT (515); bottom strand (Fig. 4), B1 (632) CAGAGGACTGTATTGA (617); B2 (599) CTGCATGTACATGGAAAACTGGCCAA (574). DNA size markers were Guanosine cleavage ladder generated by conventional LM-PCR of the al bumin enhancer treated with DMS.

\section{Acknowledgments}

We thank Art Landy and members of our laboratory for valuable discussions. The research was supported by $\mathrm{N}$ ational Institutes of Health grant GM 47903 to K.S.Z.

The publication costs of this article were defrayed in part by payment of page charges. This article must therefore be hereby marked "advertise ment" in accordance with 18 USC section 1734 solely to indicate this fact.

\section{References}

Adams, C.C., and J.L. Workman. 1995. Binding of disparate transcriptional activators to nucleosomal DNA is inherently cooperative. Mol. Cell. Biol. 15: 1405-1421.

Archer, T.K., M.G. Cordingley, R.G. Wolford, and G.L. Hager. 1991. Transcription factor access is mediated by accurately positioned nucleosomes on the mouse mammary tumor virus promoter. Mol. Cell. Biol. 11: 688-698.

Bednar, J., R.A. Horowitz, J. Dubochet, and C.L. Woodcock. 1995. Chromatin conformation and salt-induced compaction: Three-dimensional structural information from cryoelectron microscopy. J. Cel Biol. 131: 1365-1376.

Cirillo, L.A., C.E. McPherson, P. Bossard, K. Stevens, S. Cherian, E.Y. Shim, K.L. Clark, S.K. Burley, and K.S. Zaret. 1998. Binding of the winged-helix transcription factor HNF3 to a linker histone sites on the nucleosome. EMBO J. 17: (in press).

Clark, K.L., E.D. Halay, E. Lai, and S.K. Burley. 1993. Co-crystal structure of the $\mathrm{HNF} 3$ /fork head DNA recognition motif resembles histone H5. Nature 364: 412-420.

Costa, R.H. 1994. Hepatocyte nuclear factor 3/forkhead protein family: Mammalian transcription factors that possess divergent cellular expression patterns and binding specificities. In Liver gene expression (ed. F. Tronche and M. Yaniv), pp. 183-206. R.G. Landes, Austin, TX.

Fedor, M.J., N.F. Lue, and R.D. Kornberg. 1988. Statistical positioning of nucleosomes by specific protein-binding to an upstream activating sequence in yeast. J. Mol. Biol. 204: 109-127.

Felsenfeld, G. 1992. Chromatin as an essential part of the transcriptional mechanism. Nature 355: 219-223.

Fragoso, G., S. John, M.S. Roberts, and G.L. Hager. 1995. N ucleosome positioning on the MMTV LTR results from the frequency-biased occupancy of multiple frames. Genes \& Dev. 9: 1933-1947.

Godde, J.S. and A.P. Wolffe. 1995. Disruption of reconstituted nucleosomes. J. Biol. Chem. 270: 27399-27402.

Gualdi, R., P. Bossard, M. Zheng, Y. Hamada, J.R. Coleman, and K.S. Zaret. 1996. Hepatic specification of the gut endoderm in vitro: Cell signaling and transcriptional control. Genes \& Dev. 10: 1670-1682.

Han, M., U.J. Kim, P. Kayne, and M. Grunstein. 1988. Deletion of histone $\mathrm{H} 4$ and nucl eosomes activates the PHO 5 gene in Saccharomyces cerevisiae. EMBO J. 7: 2221-2228.

Hayes, J.J., T.D. Tullius, and A.P. Wolffe. 1990. The structure of DNA in a nucleosome. Proc. Natl. Acad. Sci. 87: 7405-7409.

Jackson, J.R. and C. Benyajati. 1993. DN A-histone interactions are sufficient to position a single nucleosome juxtaposing Drosophila Adh adult enhancer and distal promoter. Nucleic Acids Res. 21: 957-967.

Jackson, D.A., K.E. Rowader, K. Stevens, C. Jiang, P. Milos, and K.S. Zaret. 1993. Modulation of liver-specific transcription by interactions between hepatocyte nuclear factor 3 and nuclear factor 1 binding DNA in close apposition. Mol. Cell. Biol. 13: 2401-2410.

Kaufmann, E. and W. Knochel. 1996. Five years on the wings of fork head. Mech. Dev. 57: 3-20.
Lai, E., V.R. Prezioso, W. Tao, W.S. Chen, and J.E. Darnell, Jr. 1991 Hepatocyte nuclear factor $3 \alpha$ belongs to a gene family in mammals that is homologous to the Drosophila homeotic gene fork head. Genes \& Dev. 5: 1-12.

Liu, J.-K., C.M. DiPersio, and K.S. Zaret. 1991. Extracellular signals that regulate liver transcription factors during hepatic differentiation in vitro. Mol. Cell. Biol. 11: 773-784.

Lu, Q., L.L. Wallrath, H. Granok, and S.C.R. Elgin. 1993. (CT)n-(GA)n repeats and heat shock elements have distinct roles in chromatin structure and transcriptional activation of the Drosophila hsp26 gene. Mol. Cell Biol. 13: 2802-2814.

McPherson, C.E., E.Y. Shim, D.S. Friedman, and K.S. Zaret. 1993. An active tissue-specific enhancer and bound transcription factors existing in a precisely positioned nucleosomal array. Cell 75: 387-398.

M cPherson, C.E., R. Horowitz, C.L. Woodcock, C. Jiang, and K.S. Zaret. 1996. Nucleosome positioning properties of the albumin transcriptional enhancer. Nucleic Acids Res. 24: 397-404.

Pazin, M.J., P. Bhargava, E.P. Geiduschek, and J.T. Kadonaga. 1997. $\mathrm{Nucleosome} \mathrm{mobility} \mathrm{and} \mathrm{the} \mathrm{maintenance} \mathrm{of} \mathrm{nucleosome} \mathrm{position-}$ ing. Science 276: 809-812.

Perlmann, T., and O. Wrange. 1988. Specific gl ucocorticoid receptor binding to DNA reconstituted in a nucleosome. EMBO J. 7: 3073-3079.

Pierrou, S., M. Hellqvist, L. Samual sson, S. Enerback, and P. Carlsson. 1994. Cloning and characterization of seven human forkhead proteins: Binding site specificity and DNA bending. EMBO J. 13: 5002-5012.

Piña, B., U. Bruggemeier, and M. Beato. 1990. N ucleosome positioning modulates accessibility of regulatory proteins to the mouse mammary tumor virus promoter. Cell 60: 719-731.

Pruss, D., B. Bartholomew, J. Persinger, J. Hayes, G. Arents, E.N . M oudrianakis, and A.P. Wolffe. 1996. An asymmetric model for the nucl eosome: A binding site for linker histones inside the DN A gyres. Science 274: 614-617.

Ramakrishnan, V., J.T. Finch, V. Graziano, D.L. Lee, and R.M. Sweet. 1993. Crystal structure of globular domain of histone $\mathrm{H} 5$ and its implications for nucleosome binding. Nature 362: 219-224.

Rhodes, D. 1985. Structural analysis of a triple complex between the histone octamer, a Xenopus gene for 5S RN A and transcription factor IIIA. EMBO J. 4: 3473-3482.

Roth, S.Y., M. Shimizu, L. Johnson, M. Grunstein, and R.T. Simpson. 1992. Stable nucleosome positioning and complete repression by the yeast $\alpha 2$ repressor are disrupted by amino-terminal mutations in histone H 4. Genes \& Dev. 6: 411-425.

Schild, C., F.X. Claret, W. Wahli, and A.P. Wolffe. 1993. A nucleosome dependent static loop potentiates estrogen-regulated transcription from the Xenopus vitellogenin B1 promoter in vitro. EMBO J. 12: $423-433$

Shimizu, M., S.Y. Roth, C. Szent-Gyorgyi, and R.T. Simpson. 1991. N ucleosomes are positioned with base pair precision adjacent to the $\alpha 2$ operator in Saccharomyces cerevisiae. EMBO J. 10: 3033-3041.

Staynov, D.Z. and C. Crane-Robinson. 1988. Footprinting of linker histone $\mathrm{H} 5$ and $\mathrm{H} 1$ on the nucleosome. EMBO J. 7: 3685-3691.

Steger, D.J. and J.L. Workman. 1997. Stable co-occupancy of transcription factors and histones at the HIV-1 enhancer. EMBO J. 16: 2463-2472.

Truss, M., J. Bartsch, A. Schel bert, J.G. Haché, and M. Beato. 1995. Hormone induces binding of receptors and transcription factors to a rearranged nucleosome on the MMTV promoter in vivo. EMBO J. 14: 1737-1751.

Verdin, E., P. Paras, Jr., and C. Van Lint. 1993. Chromatin disruption in the promoter of human immunodeficiency virus type 1 during transcriptional activation. EMBO J. 12: 3249-3259.

Weigel, D., G. Jürgens, F. Küttner, E. Seifert, and H. Jäckle. 1989. The homeotic gene fork head encodes a nuclear protein and is expressed in the terminal regions of the Drosophila embryo. Cell 57: 645-658.

Zlatanova, J. and K. van Holde. 1996. The linker histones and chromatin structure: N ew twists. Progr. Nucleic Acid Res. Mol. Biol. 52: 217-259.

Zaret, K.S. 1995. N ucleoprotein architecture of the albumin transcriptional enhancer. Semin. Cell Biol. 6: 209-218.

Zaret, K.S. and K. Stevens. 1995. Expression of a highly unstable and insoluble transcription factor in E. coli: Purification and characterization of the fork head homolog HNF3 $\alpha$. Protein Expression Purification 6: 821-825. 


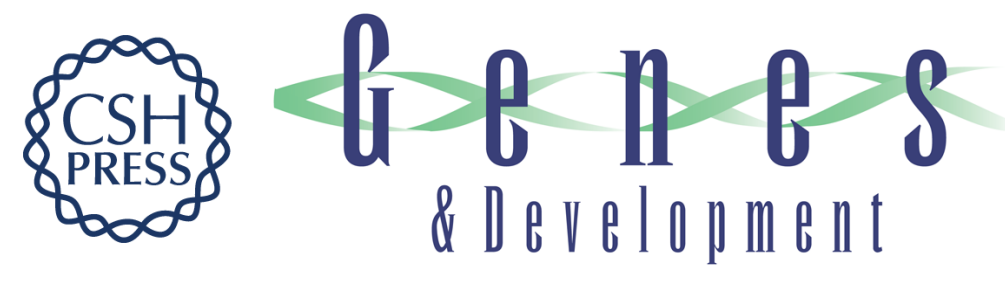

\section{Nucleosome positioning by the winged helix transcription factor HNF3}

Eun Yong Shim, Christopher Woodcock and Kenneth S. Zaret

Genes Dev. 1998, 12:

Access the most recent version at doi:10.1101/gad.12.1.5

References This article cites 37 articles, 15 of which can be accessed free at: http://genesdev.cshlp.org/content/12/1/5.full.html\#ref-list-1

License

Email Alerting Receive free email alerts when new articles cite this article - sign up in the box at the top Service right corner of the article or click here.

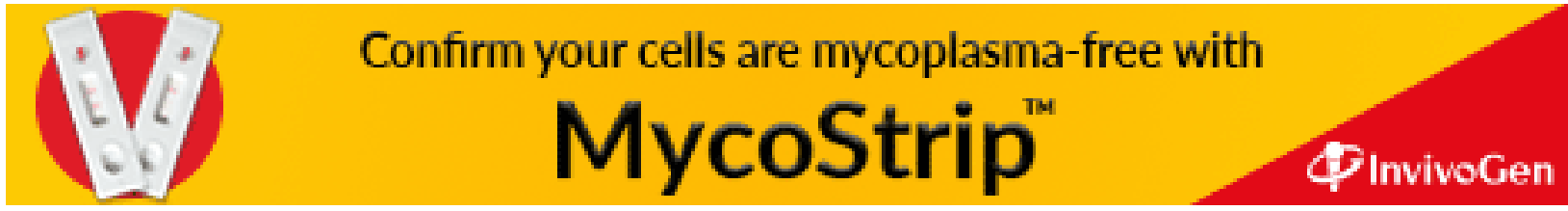

